\title{
PENYANGKALAN ADANYA TUHAN DALAM PANDANGAN ATEIS DAN SAINS MODERN
}

\author{
Herwansyah \\ Fakultas Ushuluddin dan Pemikiran Islam UIN Raden Fatah \\ Herwansyah_uin@radenfatah.ac.id
}

\begin{abstract}
The philosophy of the 19th and 20th centuries gave birth to the idea of atheism. Modern atheist figures include Ludwig Feuerbach, Karl Marx, Friedrich Nietzsche, Sigmund Freud and Jean-Paul Sartre. The denial of God presented by each of the 19th and 20th century figures has his own arguments and context. According to Feurbach God is the creation of human delusion. Karl Marx, religion is the opium of the people. Nietzsche, God is dead. Sigmund Freud, religion according to his psychological nature is an illusion. Sartre, the existence of God is nothingness. The denial of God by modern scientists does not mean not to believe in the existence of God at all, but they just have put aside the existence of God. The scientists deny the existence of God with mean to awaken, awaken the religious human beings of the social condition.
\end{abstract}

Keywords: god, atheism, modern science

\begin{abstract}
Abstrak : Filsafat abad ke 19 dan ke 20 melahirkan pemikiran ateisme. Para tokoh ateisme modern antara lain Ludwig Feuerbach, Karl Marx, Friedrich Nietzsche, Sigmund Freud dan Jean-Paul Sartre. Penyangkalan adanya Tuhan yang dikemukakan masing-masing tokoh abad ke 19 dan 20 mempuyai argumentasi dan konteksnya sendiri. Oleh karena itu agar dapat memperoleh manfaat untuk konteks kekinian, maka perlu dikaji mendalam. Ludwig, Tuhan adalah ciptan angan-angan manusia. Karl Marx, agama adalah candu rakyat. Nietzsche, Tuhan telah mati. Sigmund Freud, agama menurut kodrat psikologisnya adalah sebuah ilusi. Sigmund Freud, apabila ada Tuhan manusia itu merupakan ketiadaan. Penyangkalan adanya Tuhan oleh tokoh ilmuan modern, ternyata mereka semua bukan berarti tidak percaya akan adanya Tuhan sama sekali, kerena mereka tidak pernah menayakan Tuhan ada atau tidak. Para ilmuan tersebut menyangkal adanya Tuhan dikarenakan untuk membangkitkan, menyadarkan umat manusia beragama dimana mereka hidup dan saksikan agar maju secara peradaban.
\end{abstract}

Kata kunci : god, atheism, modern science 


\section{A. Pendahuluan}

Ateisme adalah pandangan yang menolak pendapat bahwa Tuhan itu ada, sesuai dengan kata asalnya secara etimologis, " $\boldsymbol{a}$ " yang berarti " tidak" dan "theos" adalah "dewa". Konsep "ada" dan "tiada" (eksistensi) adalah konsep filsafat, sehingga dalam tulisan ini ateisme dapat dirumuskan menjadi paham penolakan secara filosofis terhadap eksistensi Tuhan.

Fonomena ateisme merupakan salah satu fonomena yang sangat penting dalam perkembangan kehidupan spiritual. Ateisme merupakan fonomena yang mesti tumbuh dalam setiap kebudayaan ketika berada dalam fase peradaban tertentu, dan fonomenanya berbedabeda sesuai dengan spirit kebudayaan tersebut muncul di tengah-tengah masyarakat manusia modern. (Badawi, 2003:1-3)

Fonomena ateisme seringkali mendapat konfrontasi dan penolakan baik secara teoritis maupun secara praktis. Penolakan tersebut terjadi pada setiap zaman di dunia kuno, abad pertengahan (renaissance) dan zaman modern. Ateisme seringkali mencetuskan ide-ide baru yang bertentangan dengan nilai agama. Agama di anggap tidak sesuai bahkan tidak mampu untuk memecahkan problem, realitas yang dihadapi oleh umat manusia.

Sejarah ateisme di seluruh dunia sampai akhir 1700-an telah diabaikan, ditekan atau ditolak. Kesulitan sejarawan untuk pembaca ateis adalah dalam memastikan sampai sejauh mana ateisme, dalam arti kata seperti yang dipahami pada hari ini, adalah lazim di dunia kuno, abad pertengahan, renaissance, dan modern.(Berman, 1990)

Sudah menjadi tradisi dalam ilmu pengetahuan, dan lebih lagi dalam dunia filsafat bila ada ide pasti akan mendatangkan pendapat kedua dan seterusnya. Demikian pula yang terjadi di bidang agama, itu juga yang terjadi tentang penggujingan akan adanya Tuhan dan berakhir pada penyangkalan akan keberadaan-Nya, seperti yang disampaikan oleh Jean-Paul Sartre, Ludwig Feuerbach, Karl Marx, Friedrick Nietzsche, dan Sigmund Freud.

\section{B. Agama menurut Ludwig Feuerbach}

Ludwig Feuerbach (1804-1872) adalah murid Hegel, ketika ingin menjadi pendeta Protestan, ludwig belajar pada waktu itu di Berlin, Jerman. Namun dengan berjalannya waktu Ludwig menolak pemikiran Hegel. Ludwig Feuerbach adalah orang pertama yang mencoba memberikan dasar pemikiran ilmiah pada ateisme.

Menurut Hegel (1770-1831) bahwa dalam kesadaran manusia Tuhan mengungkapkan diri. Pemikiran Hegel tersebut dipahami oleh feuerbach bahwa, yang manusia pikirkan, lakukan itu yang mengatur adalah roh semesta, manusia ibarat wayang yang dimainkan oleh 
dalang. Pemikiran Hegel tersebut yang dikritik oleh Feuerbach, dianggap memutar balikkan kenyataan. Karena Hegel memberi kesan bahwa yang nyata adalah Tuhan (yang tidak kelihatan) sedangkan manusia (yang kelihatan) hanyalah sebagai wayangnya, padahal yang jelas nyata adalah manusia. Bukan manusia dan pemikiran tentang Tuhan yang merupakan roh semesta adalah produk hayalan. Tuhan adalah hasil pemikiran manusia. Tuhan bukanlah yang menciptakan manusia melainkan Tuhan adalah hasil ciptaan angan-angan manusia. Agama adalah sebuah proyeksi manusia. Tuhan, malaikat, surga dan neraka tidak mempunyai kenyataan pada dirinya sendiri, melainkan hanyalah gambaran yang dibentuk oleh manusia tentang dirinya sendiri secara imajiner, yaitu angan-angan manusia tentang hakikat dirinya sendiri.

Bagi Feuerbach, manusia secara indrawi tidak dapat dibantah, sedangkan roh semesta hanya berada sebagai objek pemikiran manusia. Feuerbach membantah claim Hagel bahwa ia mengangkat agama ke dalam rasional filsafat. Menurut Feurbach, filsafat roh sebaliknya merupakan kemenangan agama terhadap rasionalitas, karena tetap diandaikan begitu saja bahwa Tuhan adalah yang pertama, dan manusia yang kedua. Bahwa "Tuhan" oleh Hagel disebut "roh semesta" tidak mengubah kenyataan. Oleh karena itu, kritik Feurbach terhadap Hegel adalah hakikat filsafat Hegel sebenarnya adalah kepercayaan agama yang terselubung.

Menurut Feuerbach agama merupakan penyembahan manusia terhadap hasil ciptaannya sendiri yang tidak disadarinya, apa yang sebenarnya adalah angan-angan dianggap mempunyai eksistensi pada dirinya sendiri, maka manusia kemudian merasa takut dan perlu menyembah dan menghormatinya sebagai Tuhan. Dengan demikian manusia menyatakan keseganan terhadap hakikatnya sendiri dengan tidak menyadarinya. Sehingga agama mengungkapkan keterasingan manusia dari dirinya sendiri. Adapun ungkapan Feuerbach lebih lanjut adalah sebagai berikut :

Agama sekurang-kurangnya agama Kristiani, adalah kelakuan manusia terhadap dirinya sendiri, atau lebih tepat:terhadap hakikatnya sendiri,akan tetapi kelakuan terhadap hakikatnya seperti makhluk lain. Kakekat nabi bukan lain hakikat manusia, atau lebih tepat:hakikat manusia yang dipisahkan dari batas-batas manusia individual, jadi nyata, jasmani, yang diobjektifkan, artinya dipandang dan dipuja sebagai makhluk lain yang berbeda dari padanya maka dari itu semua ciri hakikat nabi adalah ciri hakikat manusia.(Magnis Suseno:2005:21)

Menurut Feuerbach manusia hanya dapat mengakhiri keterasingannya dan menjadi dirinya sendiri apabila ia meniadakan agama. Manusia harus menarik ke dalam dirinya 
sendiri. Manusia harus menolak kepercayaan Tuhan yang mahatahu, mahaadil, supaya manusia menjadi kuat, baik, adil, dan tahu. Manusia harus membongkar agama agar ia dapat merealisasikan potensi-potensinya. Agama bagi Feuerbach adalah hasil usaha manusia untuk mengembangkan diri manusia untuk merealisasikan hakikatnya, agama adalah proyeksi diri manusia.Menurut Feuerbach kepercayaan kepada Tuhan menghalangi kemajuan, pencerahan, kedewasaan dan kebebasan manusia.(Magnis Suseno, 2006:21)

\section{Agama Candu Rakyat : Karl Marx}

Karl Marx adalah penerus Feuerbach sebagai, pembela ateisme. Karl Marx juga sama seperti Feuerbach adalah penganut paham Hegel yang sejati, sampai pada tahun 1841 dibacanya buku Feuerbach tentang inti ajaran Kristen. Sejak saat itu, Marx bersama sahabatnya Friederich Engels termasuk aliran materalisme. Menurut aliran materalisme realitas yang pertama itu adalah alam materiil. Apa yang rohani tidak mendahului materi, melainkan pencerminan dari padanya.

Karl Marx terkenal dengan ucapannya tentang "agama adalah candu bagi masyarakat", yang dimaksud adalah untuk mengkritik Feuerbach yang dianggapnya tidak tuntas atau hanya berhenti di tengah jalan. Menurut Marx, benar apa yang dikatakan Feuerbach bahwa agama adalah dunia khayalan dimana manusia mencari dunianya sendiri, namun kenapa manusia melarikan diri ke dunia khayalan dari pada mewujudkan diri dalam kehidupan nyata?

Menurut Marx, karena kehidupan nyata berarti struktur kekuasaan dalam masyarakat yang tidak mengizinkan manusia untuk mewujudkan kekayaan hakikatnya, sehingga manusia melarikan diri ke dunia khayalan. Penderitaan religius adalah ekspresi penderitaan nyata dan sekaligus protes terhadap penderitaan nyata. Agama adalah keluhan makhluk terdesak, hati dunia tanpa hati, sebagaimana dia roh keadaan yang tanpa roh, agama adalah candu bagi masyarakat. Kritik terhadap agama tidak membawa manfaat, yang perlu adalah mengubah keadaan masyarakat yang membuat manusia lari ke agama karena dalam agama penderitaan dan ketertindasan manusia terungkap. Menurut Marx, agama akan menghilang dengan sendirinya, apabila manusia dapat membangun dunia yang memungkinkan manusia untuk mengembangkan hakikatnya secara nyata dan positif.

\section{D. "Tuhan Telah Mati" : Friedrick Nietzsche}

Nietzsche tidak mau mengatakan Tuhan pernah ada, Tuhan tak pernah ada, manusia yang menciptakan Tuhan (Kung, 1980:122) Tuhan yang dibunuh adalah Tuhan yang diciptakan manusia. Tuhan harus dan jadi dibunuh karena sesudah diciptakan oleh manusia, 
Tuhan menguasai manusia mengasingkannya dari dirinya sendiri dan dari dunianya Tuhan membuat manusia menjadi kerdil, dan mengkorupsi moralitasnya. Bagi Nietzsche agama adalah merupakan pelarian dari dunia yang seharusnya dihadapi apabila ia jujur, agama merupakan sentimen mereka yang kalah yang diharapkan memperoleh kemenangan di alam baka.

Menurut Nietzsche sekarang Tuhan kuno telah mati semati-matinya (Kung, 1980:136), Tuhan sebenarnya tidak mati karena tidak pernah ada. Tuhan yang mati adalah Tuhan yang ribuan tahun membelenggu hati dan pikiran manusia.

\section{E. Ateisme Modern : Sigmund Freud}

Sigmund Freud (1856-1939) merupakan bapak psikoanalisa dan merupakan salah satu ilmuan berpengaruh di dunia dan seorang ateis. Ada atau tidak adanyanya Tuhan tidak pernah ditanyakan olehnya yang jelas Tuhan tidak ada, yang ada adalah alam dengan manusia dan segala masalahnya. Bagi Sigmund Freud sudah cukup menemukan bahwa agama menurut kodrat psikologisnya merupakan sebuah ilusi manusia belaka.(Hujber, 177:140)

Menurut Sigmund Freud agama merupakan pelarian neurotis (kelakuan-kelakuan dan perasaan-perasaan yang aneh dalam arti tidak sesuai dengan kenyataan yang dihadapi) dan infantil dari realitas, manusia mencari keselamatan dari Tuhan yang tidak kelihatan dan terlihat daripada menghadapi dunia dengan segala tantangannya. Manusia dapat menghadapi tantangan dunia nyata apabila mampu membebaskan diri dari neurosis kolektif.(Freud, 1984:9)

Namun Freud mengajukan pertanyaan selanjutnya, "Apakah agama benar-benar baik bagi manusia?" Jawabannya adalah ambigu. Yang ditekankan olehnya adalah seharusnya manusia bertanya akan imannya sehingga dia tidak terjebak dalam bentuk-bentuk ide pemahaman imajanasi yang tidak rasional seperti pasien yang sakit dengan mimpi-mimpinya. Pendek kata, Freud tidak memperdebatkan realitas Tuhan, namun lebih mengupas ilusi palsu kesadaran manusia tentangnya. Karena bertanya, maka sesungguhnya penjelasan yang dikemukakan agama tidaklah memadai, Tuhan tidak bisa dijelaskan dalam intelektual, sehingga perlu ditolak juga. Terlebih lagi jika dicari manfaatnya, agama hanya sebagai penghambat perkembangan pribadi, maka harus pula ditolak.(Hujbers:141)

\section{F. Ateis Peraih Nobel : Jean-Paul Sartre}

Tuhan di mata Sartre kecil adalah sosok penghukum yang mengawasinya di manapun dia berada, oleh karenanya dia tidak suka kehadiran Tuhan. Tuhan juga tidak hadir ketika dia 
ingin menemuinya. Oleh karena itu, Sartre sudah menolak Tuhan yang tidak nyata semenjak umur 12 tahun. Bagi Jean-Paul Sartre, demi keutuhan manusia tidak mungkin ada Tuhan, hanya kalau tidak ada Tuhan, manusia dapat betul-betul menjadi dirinya sendiri karena adanya Tuhan akan mencegah manusia menjadi dirinya sendiri. Menurut Jean-Paul Sartre manusia bertanggung jawab pada dirinya sendiri serta atas semua orang (Bartens, 2001:24). Manusia bertanggung jawab atas diri sendiri, maksudnya adalah manusia sendiri yang membentuk dirinya sendiri. Manusia hanya bisa bebas jika dapat bertanggung jawab pada dirinya sendiri. Manusia tidak pernah bisa bebas jika ada Tuhan, karena semua sudah ditentukan. Apabila Ada Tuhan manusia itu merupakan ketiadaan.

Sartre yang tadi dididik secara Katolik berpindah kepada kesusastraan, yang disebut sebagai agama baru baginya. Namun secara sistematis, dan khas eksistesialis, penolakan atas Tuhan ini dilakukannya karena pemisahan radikal dalam tulisannya Ada dan Ketiadaan terjemahan dari Being and Nothingness. Baginya, di dunia ini tidak ada grand design yang mutlak, manusialah yang bisa mengatur dirinya sendiri dengan eksistensinya.

Menurut Jean-Paul Sartre, manusia bebas secara mutlak, menurutnya dalam segala hal terdapat dua bentuk: bentuk benda yang selalu telah ditentukan isinya dan bentuk manusia yang menentukan isinya sendiri. Jika manusia yang menentukan isinya sendiri maka tidak ada tempat untuk kebenaran dan nilai-nilai hidup yang tetap. Manusia sendiri memilih nilai-nilai hidup sebagai faktor perkembangannya sebagai pribadi. Oleh karena itu, tidak mungkin terdapat Tuhan, sebab Tuhan didefinisikan sebagai sumber nilai. Manusia yang ingin hidup sebagai manusia tidak menerima saingan, maka memilih manusia.

\section{Daftar Pustaka}

Bertens, Kees, Sejarah Filsafat Yunani, Yogyakarta : Kanisius, 1990, Filsafat Barat Kontemporer - Perancis, Jakarta : Gramedia, 2001

, “Sigmund Freud : Memperkenalkan Psiko-analisa", Jakarta : PT. Gramedia, 1984

Bakhtiar, Amsal, Filsafat Agama : Wisata Pemikiran dan Kepercayaan Manusia, Jakarta : PT. Rajagrafindo Persada, 2014

Huijber, Theo, Mencari Allah Pengantar ke Dalam Filsafat Ketuhanan, Yogyakarta : Kanisius, 1992

Hans Kung, Does God Exist? An Answer for Today, Trj. E.Quin, London: Collins, 1980 
ISSN: 2443-0919

JIA/Juni 2017/Th.18/Nomor 1

Hume, David, An Enquiry Concerning Human Understanding, Chicago : Chicago University, 1952

Suseno, Franz Magnis, Menalar Tuhan, Yogyakarta: Kanisius 2006 
